\title{
Morphine Interaction with Aspirin: a Double-Blind, Crossover Trial in Healthy Volunteers
}

\author{
Johann Bartko, Christian Schoergenhofer, Michael Schwameis, Patricia Wadowski, \\ Jacek Kubica, Bernd Jilma, and Eva-Luise Hobl \\ Department of Clinical Pharmacology, Medical University of Vienna (J.B., C.S., M.S., P.W., B.J., E.-L.H.), and Ludwig Boltzmann \\ Institute of Osteology, Hanusch Hospital of WGKK, AUVA Trauma Centre Meidling (J.B.), Vienna, Austria; and Collegium \\ Medicum, Nicolaus Copernicus University, Bydgoszcz, Poland (J.K.)
}

Received December 14, 2017; accepted February 23, 2018

\begin{abstract}
Aspirin is a cornerstone in the antiplatelet therapy for acute coronary syndromes. Coadministration of morphine may potentially influence the intestinal absorption, pharmacokinetics, and pharmacodynamics, as seen with $\mathrm{P}_{2} \mathrm{Y}_{12}$ inhibitors. In this trial, healthy volunteers were randomized to receive morphine ( $5 \mathrm{mg}$, i.v. bolus injection) at one of seven different time points before, after, or with aspirin (162 mg, p.o.) in a double-blind, placebo-controlled fashion. After a 14-day washout, subjects received placebo instead of morphine. Pharmacokinetics were determined by liquid

chromatography, and aspirin's effects were measured by platelet function tests (whole-blood platelet aggregation: multiplate, platelet plug formation: PFA-100). Morphine increased the total acetylsalicylic acid exposure by $20 \%$ compared with placebo when given simultaneously with aspirin, whereas $C_{\max }$ and $t_{\max }$ were not altered. Morphine had no significant effect on aspirin-induced platelet inhibition. In contrast to coadministration with $\mathrm{P}_{2} \mathrm{Y}_{12}$ inhibitors, morphine appears to have negligible interaction with aspirin.
\end{abstract}

\section{Introduction}

For more than half a century, morphine has been used for pain relief in the clinical management of myocardial infarction (Bruce and Bing, 1965). Morphine has long been recommended as the drug of choice for chest pain relief in patients with ST-elevation myocardial infarction (Amsterdam et al., 2014) and in patients with non-STelevation acute coronary syndromes (NSTE-ACS) refractory to anti-ischemic medication (O'Gara et al., 2013). The rationale of use is based on the strong analgesic-anxiolytic effects and on a veno-dilatational component, thereby reducing heart rate and systolic blood pressure (McCarthy et al., 2016); however, observational studies have challenged the concept that the clinical benefit of morphine outweighs its risks (Meine et al., 2005; de Waha et al., 2015). In a retrospective data analysis of the CRUSADE National Quality Improvement Initiative, morphine use was associated with a higher mortality in 57,039 patients with NSTE ACS (Meine et al., 2005). More recently, a large retrospective study showed that morphine was associated with a longer hospital stay and a larger infarct size in invasively managed NSTE-ACS patients (McCarthy et al., 2017). Since morphine has never been tested in a randomized controlled trial

The Austrian Science Funds (FWF) funded this work [Grant SFB54-P04]. https://doi.org/10.1124/jpet.117.247213.
(Parodi, 2016), it is not known whether morphine administration in patients with acute coronary syndromes improves clinical outcome.

With the advent of new therapies, combination of several drugs increases the chance of drug-drug interaction. Morphine and fentanyl can decrease plasma levels and/or antiplatelet effects of oral $\mathrm{P}_{2} \mathrm{Y}_{12}$ receptor antagonists (Hobl et al., 2014, 2016a,b; Kubica et al., 2016a; McEvoy et al., 2018), which may be explained by an impaired drug absorption, probably as a consequence of delayed gastric emptying, as shown for acetaminophen (Nimmo et al., 1975). This delayed effect may be overcome by intravenous infusion of platelet inhibitors such as abciximab (SillerMatula et al., 2016) or cangrelor (Bhatt et al., 2013). Although infusion of aspirin rapidly inhibits platelets in patients with myocardial infarction (Fuchs et al., 2010), chewable aspirin is currently recommended in guidelines (Amsterdam et al., 2014). Given that approximately one third of patients with acute coronary syndrome receive intravenous morphine simultaneously with aspirin, it is clinically relevant whether morphine also affects the pharmacokinetics (PK) and pharmacodynamics (PD) of aspirin. We hypothesized that morphine may alter the plasma levels of aspirin and therefore its antiplatelet activity. A randomized, crossover trial in healthy volunteers was performed to investigate the effect of morphine on the $\mathrm{PK}$ and $\mathrm{PD}$ of aspirin.

ABBREVIATIONS: AA, arachidonic acid; ASA, acetylsalicylic acid; AUC, area under the concentration-time curve; CEPI, collagen/epinephrine; CEPI-CTs, collagen-/epinephrine-induced closure time; CT, closure time; MEA, multiple electrode aggregometry; NSTE-ACS, non-ST-elevation acute coronary syndromes; PD, pharmacodynamics; PK, pharmacokinetics; SA, salicylic acid; $t_{\mathrm{max}}$, time to reach maximum concentration. 


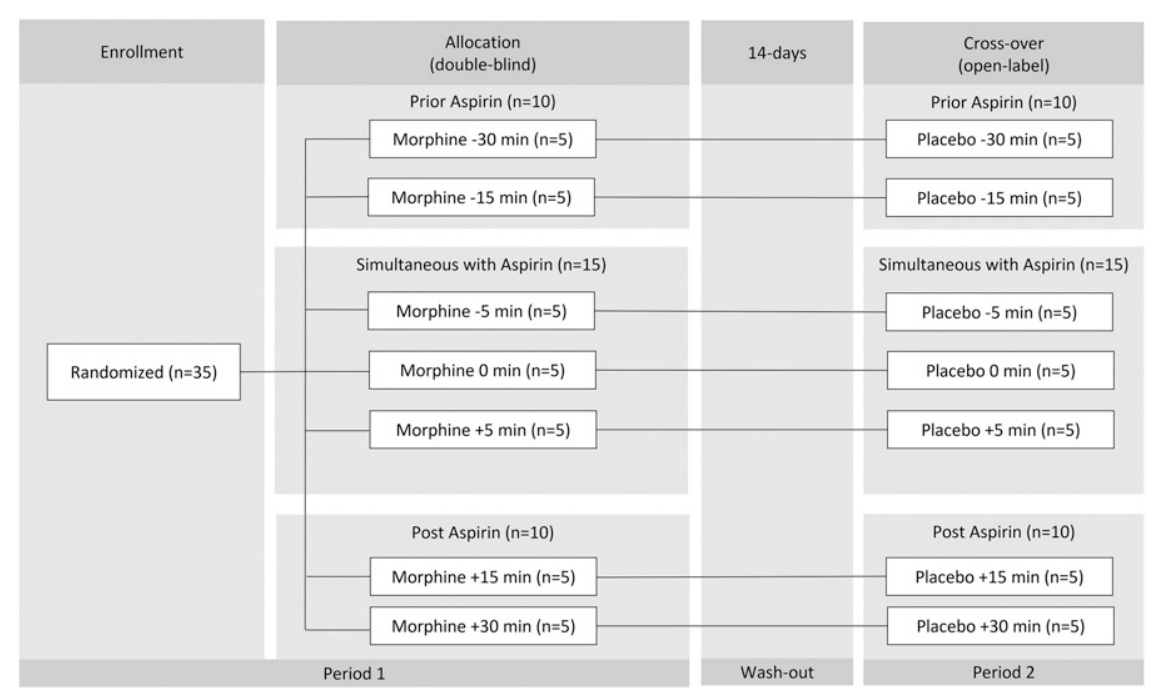

Fig. 1. Schematic of the trial design. To define the optimal time for morphine administration, subjects were randomized to receive $5 \mathrm{mg}$ of i.v. morphine at one of seven different time points coadministered with $162 \mathrm{mg}$ of aspirin. As predefined, withinsubjects comparisons between periods were performed for pooled times of morphine injection relative to aspirin: prior $[-30,-15$ minutes]; simultaneous $[-5,0,+5$ minutes]; post $[+15,+30$ minutes $]$.

\section{Materials and Methods}

The trial was conducted at the Department of Clinical Pharmacology, Medical University of Vienna, in accordance with the Declaration of Helsinki and International Conference on Harmonization - Good Clinical Practice (ICH-GCP) (registered at clinicaltrials.gov as NCT01369186). The subjects gave written informed consent before enrollment. After an overnight fast, subjects were randomized to receive a 5-mg i.v. bolus injection of morphine (G.L. Pharma GmbH, Lannach, Austria) at one of seven different time points in the range of 30 minutes before to 30 minutes after chewing $162 \mathrm{mg}$ of enteric coated aspirin (two tablets of 81-mg chewable low-dose "baby" aspirin; Bayer HealthCare, Morristown, NJ). Block randomization was performed by using the open access randomization generator www.randomization. com.

Subjects. Healthy female and male subjects aged $\geq 18$ years were eligible for enrollment. Subjects had to stop any intake of nonsteroidal antirheumatic drugs, including aspirin and $\mathrm{P}_{2} \mathrm{Y}_{12}$ inhibitors 14 days before study entry.

Trial Design. A randomized, double-blind, and placebo-controlled trial followed by an open-label, fixed-sequence, two-period crossover was conducted in 35 healthy subjects to evaluate the potential effect of morphine (5 mg i.v. bolus injection) on intestinal absorption, PK, and PD of aspirin.

To define the optimal time for morphine administration, subjects were randomized to receive morphine at one of seven different time points in the range of 30 minutes before to 30 minutes after the administration of $162 \mathrm{mg}$ of aspirin. Each group included five subjects (Fig. 1). When the seven different times of morphine administration were compared, no differences in the PK and PD of aspirin between morphine and placebo were found (data not shown). As predefined in the study protocol, the times of morphine injection relative to aspirin were pooled [prior $(-30,-15$ minutes), simultaneous $(-5,0,+5 \mathrm{~min}-$ utes), "post" $(+15,+30$ minutes $)]$ and compared with placebo. PK profiles and $\mathrm{PD}$ response were monitored 30 and 0 minutes before and $5,15,20,30,45,60,90,120,180,240$, and 360 minutes after oral administration of aspirin during period 1 (morphine) and period 2 (placebo).

Pharmacokinetics. Acetylsalicylic acid (ASA) and salicylic acid (SA) were analyzed by high-performance liquid chromatography as previously described (Hobl et al., 2013). PK variables included the maximum plasma concentration $\left(C_{\max }\right)$, half-life $\left(t_{1 / 2}\right)$, time to reach maximum concentration $\left(t_{\max }\right)$, area under the concentration-time curve (AUC) from time zero extrapolated to infinity $\left(\mathrm{AUC}_{0_{-\infty}}\right)$ and were derived from plasma ASA and SA concentrations by a noncompartmental analysis using Kinetica 2000, version 3.0 (InnaPhase Corporation, Philadelphia, PA).
Pharmacodynamics. Multiple electrode aggregometry (MEA) (Multiple Platelet Function Analyzer/Multiplate Analyzer; Dynabyte Medical, Munich, Germany) was used to measure inhibition of arachidonic acid (AA) $(0.5 \mathrm{nM})$ induced platelet aggregation (Spiel et al., 2011). MEA data are expressed in arbitrary units (U). Sufficient platelet inhibition was defined by a value of $\leq 30 \mathrm{U}$ (Spiel et al., 2011; Jakl et al., 2017). Platelet function under high shear rates was measured by the Platelet Function Analyzer-100 system (PFA-100; Siemens Healthcare Diagnostics, Vienna, Austria) using collagen/ epinephrine (CEPI) cartridges. Time to formation of a platelet plug (CT, closure times) is expressed in seconds.

Sample Size and Statistical Analysis. Since there was no estimate for the size of the effect (intraindividual differences between periods), it was assumed to be comparable to acetaminophen. In healthy volunteers, the $t_{\max }$ of acetaminophen was observed at $22 \pm 9$ [S.D.] minutes under control conditions and after $114 \pm 72$ [S.D.] minutes when pethidine was administered before acetaminophen intake. In this study, four subjects were sufficient to demonstrate the negative effect of opiates (Nimmo et al., 1975). To check the assay sensitivity of our experimental model, eight volunteers with the randomization numbers $>14$ received $1000 \mathrm{mg}$ of acetaminophen in addition to $162 \mathrm{mg}$ aspirin on both occasions.

Data are presented as means for demographic data and medians for outcome variables in the text and descriptively, as appropriate. Outcome variables were compared with the Wilcoxon test.

\section{Results}

\section{Demographic Characteristics of Subjects and Adverse Events}

Healthy volunteers ( 10 women, 25 men) were $31 \pm 9$ years of age, weighed $77 \pm 14 \mathrm{~kg}$, and had a body mass index of $24 \pm 3 \mathrm{~kg} / \mathrm{m}^{2}$. Morphine injection caused mild to moderate adverse events in $43 \%$ of subjects, including head pressure (14\%), prickling (11\%), and flushing (6\%). No adverse effects involving the gastrointestinal tract (e.g., vomiting, nausea) and no clinical signs of an opioid-induced direct histamine release (hemodynamic changes or anaphylactoid reactions) were seen.

\section{Pharmacokinetics}

Aspirin. Morphine increased the total ASA exposure (AUC) by $\sim 20 \%$ (median, $P=0.0084$ ) when administered simultaneously with aspirin compared with placebo (Fig. 2; 


\section{Prior Aspirin}

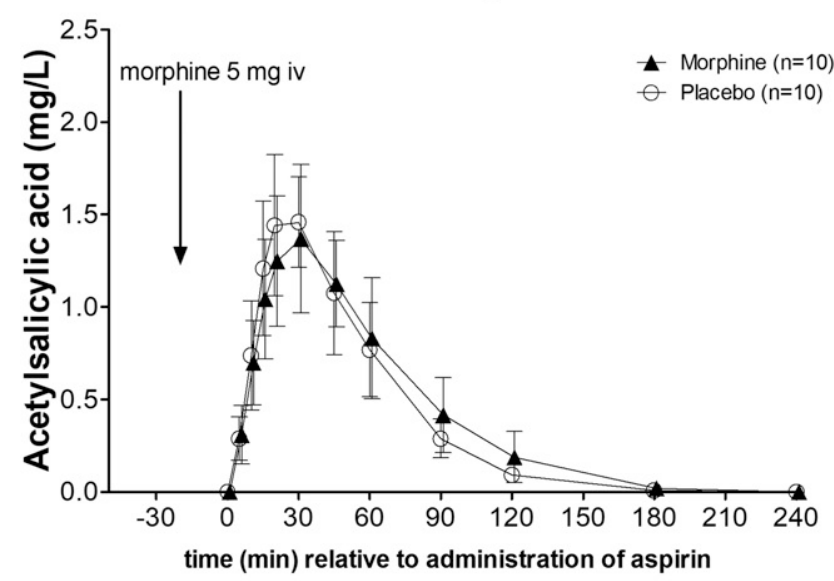

\section{Simultaneous with Aspirin}
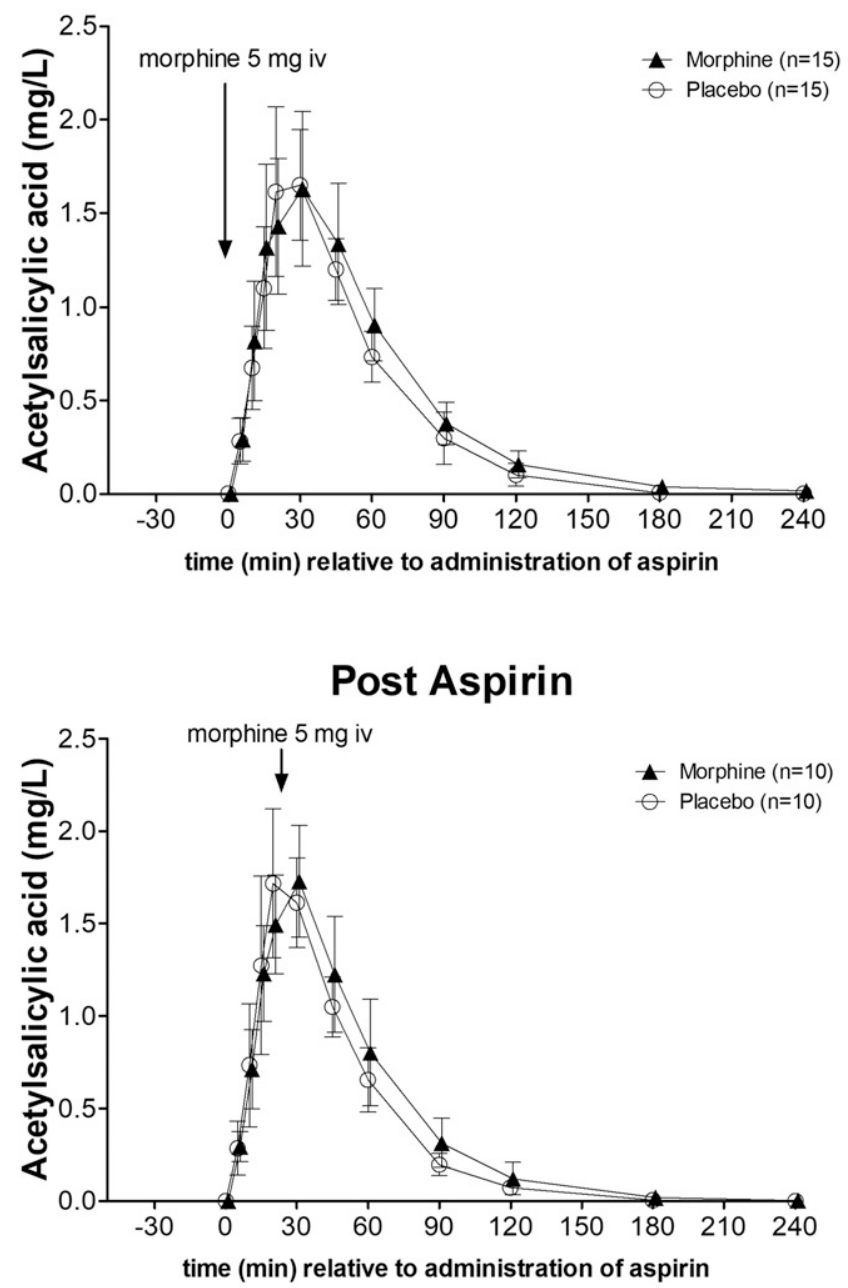

Fig. 2. Morphine interaction with aspirin. Morphine increased total ASA exposure (AUC) by $\sim 20 \%(P<0.01)$ when administered simultaneously with aspirin compared with placebo. Healthy subjects received $5 \mathrm{mg}$ of morphine (i.v.) or placebo before $(-30,-15$ minutes, $n=10)$, simultaneously $(-5,0,+5$ minutes, $n=15)$, or post $(+15,+30$ minutes, $n=10)$ $162 \mathrm{mg}$ of aspirin (p.o.). Data present means (95\% CI).
Table 1). No significant differences were detected when morphine was given before or after aspirin. Morphine had no significant effect on $C_{\max }$ and $t_{\max }$ of ASA or on the PK of salicylic acid (Table 1).

Acetaminophen. Morphine increased the $t_{\max }$ 2.3-fold and decreased the $C_{\max }$ by $27 \%$ compared with placebo (Table 1). Morphine had no significant effect on the total acetaminophen exposure (AUC) (Table 1).

\section{Pharmacodynamics}

PFA-100. Baseline ( -30 minutes) CEPI closure times (CTs) correlated well between period 1 (morphine) and period 2 (placebo) (median: 171 seconds vs. 176 seconds; Spearman $r=0.68, P<0.0001$ ). Morphine (period $1 \mathrm{vs}$. period 2) and its time of infusion (before vs. simultaneous to vs. after aspirin; period 1) had no significant effect on CEPI-CTs compared with placebo (Fig. 3). Aspirin, coadministered with morphine, increased CEPI-CTs by $46 \% 20$ minutes after administration. Similarly, CEPI-CTs increased by $57 \%$ with placebo. Maximal platelet inhibition (i.e., CEPI-CTs $>301$ seconds) occurred in 27 subjects $(77 \%)$ receiving morphine and in 31 subjects $(86 \%)$ receiving placebo within 20 minutes. All subjects receiving placebo and 33 subjects $(94 \%)$ receiving morphine reached maximal platelet inhibition within 60 minutes after aspirin intake.

Multiple Electrode Aggregometry. Baseline values ( -30 minutes) of AA-induced platelet aggregation correlated moderately between period 1 (morphine) and period 2 (placebo) (median: $79 \mathrm{U}$ vs. $83 \mathrm{U}$; Spearman $r=0.47, P=0.0042$ ). Morphine and its time of administration had no significant effect on AA-induced platelet aggregation compared with placebo (Fig. 4). Aspirin, coadministered with morphine, decreased AA-induced platelet aggregation by $69 \% 20$ minutes after administration. Equal in size, AA-induced platelet aggregation decreased by $69 \%$ with placebo. Sufficient platelet inhibition (i.e., AUC $\leq 30 \mathrm{U}$ ) occurred (within 20 minutes) in 24 subjects $(69 \%)$ receiving morphine and in 24 subjects $(69 \%)$ receiving placebo. Nearly all subjects reached sufficient platelet inhibition within 30 minutes of aspirin administration (placebo: 32/35; morphine: 31/35).

\section{Discussion}

The use of aspirin reduces mortality in patients with acute coronary syndrome. Current guidelines recommend chewed ingestion without any delay (Amsterdam et al., 2014). Although there is growing evidence that morphine slows intestinal absorption of oral $\mathrm{P}_{2} \mathrm{Y}_{12}$ inhibitors, no studies have investigated whether morphine interacts with aspirin. In this study, we investigated the effect of morphine on the PK and PD of aspirin in healthy volunteers. Studies from the mid-1970s demonstrated that opiates inhibit gastric emptying and retard the absorption of orally administered drugs. In healthy volunteers, intramuscular injection of $10 \mathrm{mg}$ of diamorphine (which is twice as potent as morphine) increased the $t_{\max }$ of acetaminophen 6.5-fold (Nimmo et al., 1975). Considering that our subjects received $5 \mathrm{mg}$ of morphine ( 4 -fold lower potency than $10 \mathrm{mg}$ of diamorphine), we observed a comparable 2.3-fold increase in $t_{\max }$ in our proof-of-concept study. Other experimental studies, in which the acetaminophen absorption test was used, reported 
TABLE 1

Summary statistics for aspirin pharmacokinetic parameters by treatment time point and acetaminophen (internal control) Values are represented as median (interquartile range).

\begin{tabular}{|c|c|c|c|c|c|c|c|}
\hline ASA & \multicolumn{4}{|c|}{ Period 1 (Morphine, $5 \mathrm{mg}$ i.v. Bolus Injection) } & \multicolumn{3}{|c|}{ Period 2 (Placebo) } \\
\hline Prior aspirin $(-30,-15 \mathrm{~min})$ & 10 & $1.5(1.1-2.0)$ & $30(28-45)$ & $90(70-103)$ & $1.8(1.4-1.9)$ & $30(20-30)$ & $84(60-103)$ \\
\hline Post aspirin $(+15,+30 \mathrm{~min})$ & 10 & $1.8(1.5-2.1)$ & $25(20-30)$ & $90(67-123)$ & $1.9(1.4-2.3)$ & $20(20-30)$ & $82(72-92)$ \\
\hline $\begin{array}{l}\text { Pooled }(-30,-15,-5,0 \\
\quad+5,+15,+30 \mathrm{~min}) \\
\text { Salicylic acid }\end{array}$ & 35 & $1.8(1.4-2.1)$ & $30(20-30)$ & $98(73-118)^{* * *}$ & $1.7(1.4-1.9)$ & $30(20-30)$ & $82(67-94)$ \\
\hline $\begin{array}{l}\text { Simultaneous with aspirin } \\
\quad(-5,0,+5 \mathrm{~min})\end{array}$ & 15 & $6.7(6.1-9.0)$ & $60(60-90)$ & $1793(1429-2478)$ & $7.6(6.7-8.4)$ & $60(60-60)$ & $1590(1378-1958)$ \\
\hline Post aspirin $(+15,+30 \mathrm{~min})$ & 10 & $7.0(6.6-9.0)$ & $60(45-90)$ & $1557(1373-2451)$ & $7.1(6.6-9.1)$ & $60(60-90)$ & $1455(1397-2553)$ \\
\hline $\begin{array}{l}\text { Pooled }(-30,-15,-5,0 \\
\quad+5,+15,+30 \mathrm{~min}) \\
\text { Acetaminophen }\end{array}$ & 35 & $6.7(6.1-8.3)$ & $60(60-90)$ & $1700(1408-2142)^{*}$ & $7.3(6.5-8.4)$ & $60(60-90)$ & $1532(1395-1923)$ \\
\hline Prior aspirin $(-30,-15 \mathrm{~min})$ & 4 & $13(8-17)$ & $90(90-90)$ & $253(1790-4252)$ & $15(11-18)$ & $45(19-83)$ & $2395(1379-4020)$ \\
\hline
\end{tabular}

AUC, area under the concentration-time curve; $C_{\max }$, maximum plasma concentration; $\mathrm{t}_{\max }$, time to maximum plasma concentration.

$* P<0.05 ; * * P<0.01 ; * * P<0.001$ vs. placebo.

similar results (Bennett et al., 1994; Yuan et al., 1998). Therefore, our experimental design achieved sufficient assay sensitivity to investigate drug-drug interactions with aspirin. Interestingly, morphine coadministration had no significant effect on aspirin-induced platelet inhibition and virtually no effect on the PK of aspirin. This was an unexpected finding because aspirin, like acetaminophen, is thought to be absorbed mainly by the small intestine (Schrör 2016).

Time to $50 \%$ gastric emptying after ingestion of $500-700 \mathrm{ml}$ of technetium-99m labeled solution occurs on average after 12 minutes under physiologic conditions (Chaudhuri, 1974). In healthy volunteers receiving diamorphine, the mean time to $50 \%$ gastric emptying of ingested solution was $>130$ minutes compared with 11.9 minutes in the control group (Nimmo et al., 1975). Because morphine more than doubles the $t_{\max }$ of acetaminophen, one would expect a significant delay in reaching maximal plasma concentrations (delayed $t_{\max }$ ) for aspirin as well; however, this was not the case, suggesting that the concept of the small intestine being the main compartment of aspirin absorption might have some shortcomings.

First, aspirin reached maximal plasma concentrations 15 minutes earlier than acetaminophen (30 minutes vs. 45 minutes, Mann-Whitney test, uncorrected $P$ value 0.0308 ), indicating a different rate of absorption. Second, morphine did not change the time to peak exposure $\left(t_{\max }\right)$, showing that delayed gastric emptying was not the rate-limiting step in absorption. Third, sufficient platelet inhibition occurred within 15-20 minutes, whether morphine was given or not.

A study comprising healthy volunteers reported that $\sim 30 \%$ of a $0.1 \mathrm{M} \mathrm{HCl}$ aspirin solution introduced into the stomach is absorbed by the gastric mucosa within 20 minutes (Hogben et al., 1957). Given that $50 \mathrm{mg}$ of intravenous ASA already completely inhibits AA-induced platelet aggregation (Boger et al., 1993), it is likely that sufficient amounts of aspirin entered the presystemic circulation in our trial.
The antiplatelet effect of aspirin is mediated by the acetyl group of ASA (Roth and Majerus, 1975). Thus, ASA, and not its primary metabolite SA, irreversibly inhibits cyclooxygenase-1 in platelets. Mean ASA exposure and maximal ASA concentrations are $\sim 10$-fold higher in the gastric tissue compared with the proximal duodenum in rats (Lichtenberger et al., 2016). This indicates that the stomach mucosa is an effective site of absorption of the nonhydrolyzed, platelet-targeting form of aspirin.

Another important factor is that aspirin can cross the oral mucosa (Schrör, 2016; Mollace et al., 2017), albeit published data on buccal absorption are scarce. Given that ASA and SA were detectable as early as 5 minutes after intake in all the subjects, the oral mucosa was likely a site of absorption. This result is in line with a study in healthy volunteers, in which ASA was already present in plasma 3 minutes after chewing aspirin (Feldman and Cryer, 1999).

According to the ion-trapping hypothesis, aspirin, a weak acid, is available primarily as a unionized, lipid-soluble form at the $\mathrm{pH}$ of the gastric juice and therefore passes the gastric mucosa rapidly. The steep $\mathrm{pH}$ gradient between gastric mucosa and gastric juice prevents aspirin from back diffusion. Because aspirin's solubility depends on $\mathrm{pH}$ (poorly soluble under acidic conditions), however, the stomach is thought to absorb only a minor fraction of aspirin (Schrör, 2016). In our study, aspirin was chewed, and it appears plausible that the high basal $\mathrm{pH}(\sim 7)$ of the salivary juice favored the dissolution of aspirin.

Another finding was that morphine increased the total ASA exposure (AUC) by $\sim 20 \%$ when administered simultaneously with aspirin compared with placebo (Fig. 2; Table 1). Such a change is of limited consequence because a minimum of a 1.25fold increase in the AUC is required to be labeled as a "minor" drug-drug interaction (Wiggins et al., 2016); however, visual investigation of the concentration-time profiles revealed that the descending limbs of the concentration-time curve were consistently higher, no matter whether morphine was given 


\section{Prior Aspirin}

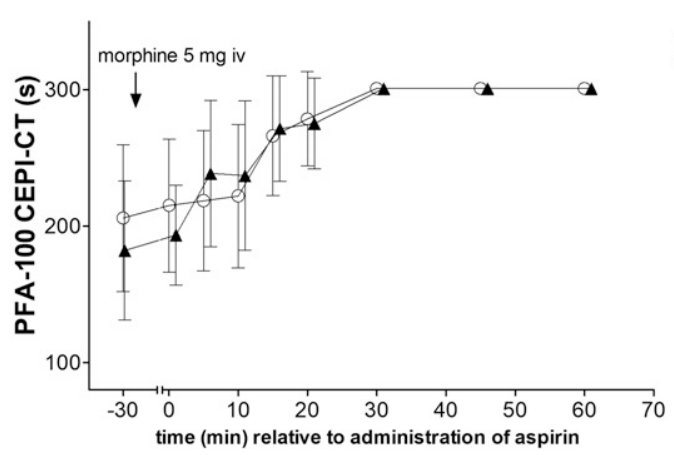

Simultaneous with Aspirin

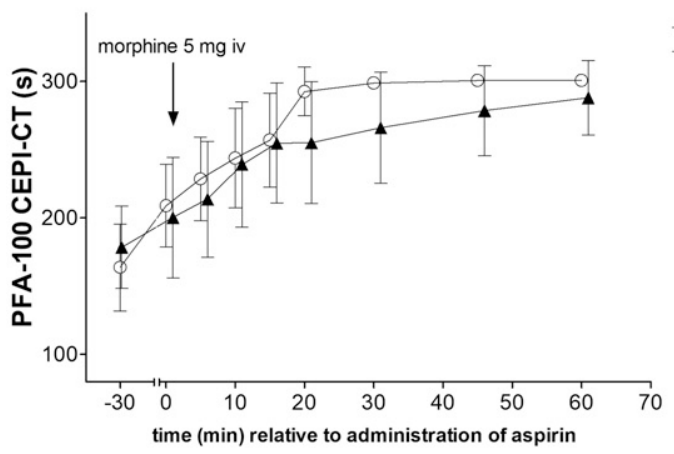

Post Aspirin

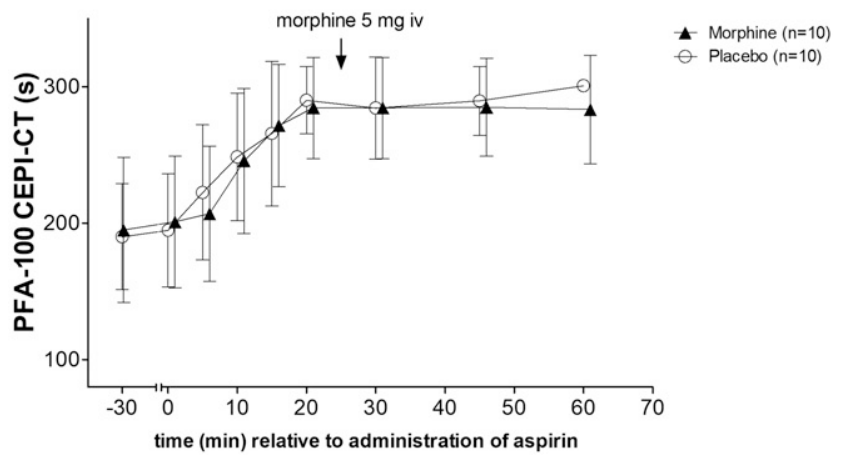

Fig. 3. Morphine interaction with aspirin. Morphine and its time of administration (prior vs. simultaneous vs. post aspirin) had no significant effect on CEPI-CTs compared with placebo. Healthy subjects received $5 \mathrm{mg}$ of morphine (iv) or placebo before $(-30,-15$ minutes, $n=10)$, simultaneously $(-5,0,+5$ minutes, $n=15)$, or post $(+15,+30$ minutes, $n=$ 10) $162 \mathrm{mg}$ of aspirin (p.o.). Data present means (95\% CI). CEPI-CT, collagen-/epinephrine-induced closure time.

before or after aspirin. Interestingly, the concentration-time curve of acetaminophen showed similar behavior. It is well documented that opioids increase the transit time in the small bowel (Kurz and Sessler, 2003), and therefore the increase in AUC may be caused by the increased contact time with the intestinal mucosa.

The minor effect of morphine on aspirin's PK was also evident in PD responses. Regardless of the time of administration, morphine had no influence on aspirin-induced platelet

\section{Prior Aspirin}

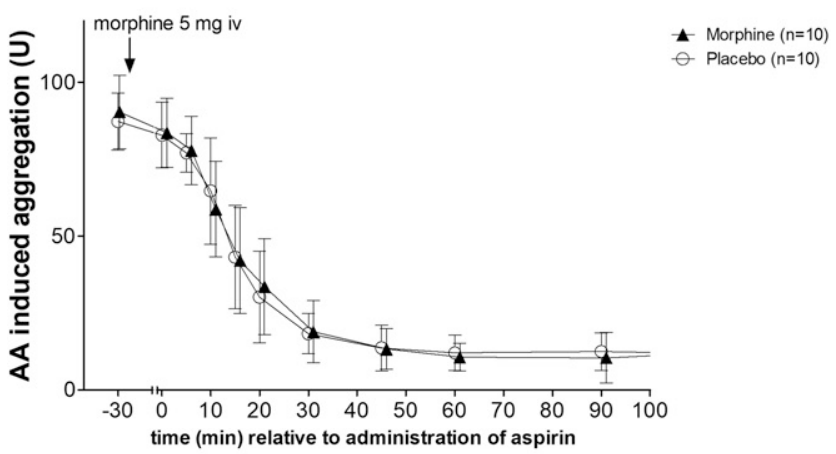

\section{Simultaneous with Aspirin}

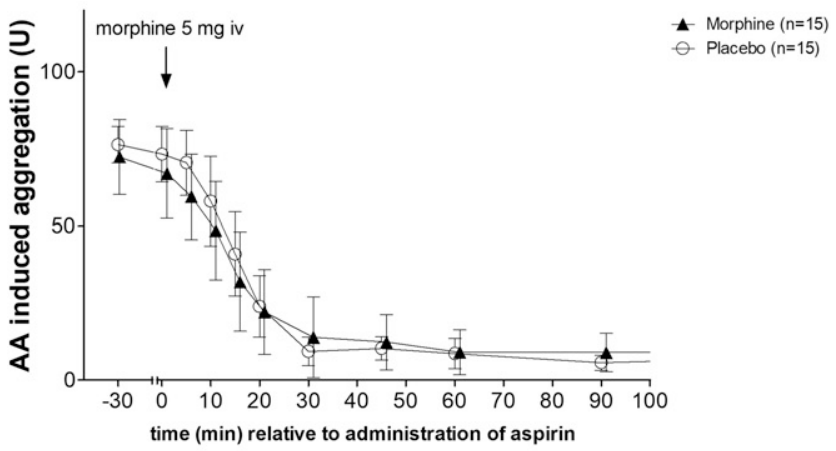

\section{Post Aspirin}

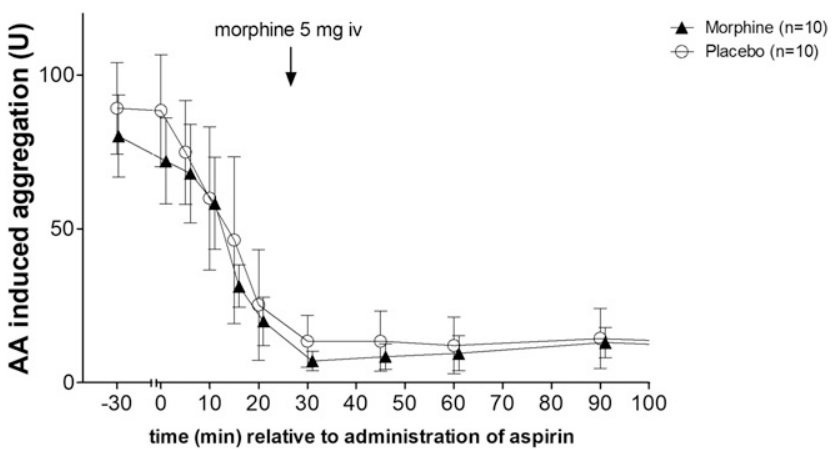

Fig. 4. Morphine interaction with aspirin. Morphine and its time of administration (prior vs. simultaneous vs. post aspirin) had no significant effect on AA $(0.5 \mathrm{nM})$ induced platelet aggregation compared with placebo. Healthy subjects received $5 \mathrm{mg}$ of morphine (i..v) or placebo before $(-30,-15$ minutes, $n=10)$, simultaneously $(-5,0,+5$ minutes, $n=15$ ), or post ( $+15,+30$ minutes, $n=10) 162 \mathrm{mg}$ of aspirin (p.o.). Data present means $(95 \% \mathrm{CI})$.

inhibition. Aspirin alone sufficiently inhibited platelet aggregation within 20 minutes, as measured by impedance aggregometry and the platelet function analyzer. This is in accordance with previous investigations in which chewed enteric coated aspirin inhibited platelet aggregation and thromboxane B2 production at the first measured time point (15 minutes after intake) (Jimenez et al., 1992).

Contemporary ACS guidelines recommend treatment with aspirin as early as possible. The combination of aspirin with a 
P2Y12 receptor inhibitor was proven more effective than aspirin alone (Yusuf et al., 2001). Controversy exists about the timing of the initiation of the P2Y12 receptor blockade (Sibbing et al., 2016). Whether P2Y12 receptor blockade should be initiated early may depend on different factors, such as time to PCI, level of certainty of diagnosis, or bleeding diathesis. A possible contributing cause may be an impaired drug absorption induced by morphine (Kubica et al., 2016b). For example, a multicenter, randomized, double-blind study in 1862 patients with ST elevation myocardial infarction compared prehospital (in the ambulance) versus in-hospital (in the catheterization laboratory) treatment with ticagrelor and found no improvement in coronary reperfusion (Montalescot et al., 2014). As patients who did not receive morphine benefit from prehospital administration of ticagrelor, the investigators suggested that morphine coadministration might delay the action of ticagrelor. In support of this hypothesis, a recent randomized, controlled trial showed that morphine delayed the antiplatelet effects of ticagrelor in patients with acute myocardial infarction (Kubica et al., 2016a). Our trial was designed to investigate the effect of morphine on the PK and $\mathrm{PD}$ of aspirin. We could demonstrate that morphine has no significant effect on aspirin-induced platelet inhibition in healthy volunteers. This may be different in ACS patients in which gastrointestinal resorption is impaired (Bochner and Lloyd, 1995), and the used doses of morphine are possibly higher. Accordingly, PK/PD interactions between morphine and aspirin cannot be completely excluded but seem unlikely in ACS patients. The final proof can be determined only by an adequately powered randomized, placebo-controlled trial in the target population, which requires a careful design and planning owing to ethical reasons. In case of uncertainty, an i.v. formulation of ASA is available and has an immediate onset of action in patients with myocardial infarction (Fuchs et al., 2010).

In conclusion, whereas morphine has negative effects on oral P2Y12 inhibitors (Kubica et al., 2016a), it slightly enhances exposure to aspirin, but platelet inhibition is not affected.

\section{Acknowledgments}

We thank Sabine Schranz, Christa Drucker, Karin Petroczi, and Christa Firbas for their technical assistance.

\section{Authorship Contributions}

Participated in research design: Jilma, Hobl.

Conducted experiments: Bartko, Schoergenhofer, Schwameis, Jilma, Hobl.

Performed data analysis: Bartko, Jilma, Hobl

Wrote or contributed to the writing of the manuscript: Bartko, Schoergenhofer, Schwameis, Wadowski, Kubica, Jilma, Hobl.

\section{References}

Amsterdam EA, Wenger NK, Brindis RG, Casey DE, Jr, Ganiats TG, Holmes DR, Jr, Jaffe AS, Jneid H, Kelly RF, Kontos MC, et al. ACC/AHA Task Force Members (2014) 2014 AHA/ACC guideline for the management of patients with non-STelevation acute coronary syndromes: a report of the American College of Cardiology/American Heart Association Task Force on practice guidelines [published correction appears in Circulation (2014) 130:e433-e434]. Circulation 130 e344-e426.

Bennett MW, Shah MV, and Bembridge JL (1994) A comparison of the effect on gastric emptying of alfentanil or morphine given during anaesthesia for minor surgery. Anaesthesia 49:155-156.

Bhatt DL, Stone GW, Mahaffey KW, Gibson CM, Steg PG, Hamm CW, Price MJ, Leonardi S, Gallup D, Bramucci E, et al.; CHAMPION PHOENIX Investigators (2013) Effect of platelet inhibition with cangrelor during PCI on ischemic events. $N$ Engl J Med 368:1303-1313.
Bochner F and Lloyd JV (1995) Aspirin for myocardial infarction. Clinical pharmacokinetic considerations. Clin Pharmacokinet 28:433-438.

Böger RH, Bode-Böger SM, Gutzki FM, Tsikas D, Weskott HP, and Frölich JC (1993) Rapid and selective inhibition of platelet aggregation and thromboxane formation by intravenous low dose aspirin in man. Clin Sci (Lond) 84:517-524.

Bruce TA and Bing RJ (1965) Clinical management of myocardial infarction. JAMA 191:124-126.

Chaudhuri TK (1974) Use of 99mTc-DTPA for measuring gastric emptying time. J Nucl Med 15:391-395.

de Waha S, Eitel I, Desch S, Fuernau G, Lurz P, Urban D, Schuler G, and Thiele H (2015) Intravenous morphine administration and reperfusion success in ST-elevation myocardial infarction: insights from cardiac magnetic resonance imaging. Clin Res Cardiol 104:727-734.

Feldman M and Cryer B (1999) Aspirin absorption rates and platelet inhibition times with 325-mg buffered aspirin tablets (chewed or swallowed intact) and with buffered aspirin solution. Am J Cardiol 84:404-409.

Fuchs I, Spiel AO, Frossard M, Derhaschnig U, Riedmüller E, and Jilma B (2010) Platelet hyperfunction is decreased by additional aspirin loading in patients presenting with myocardial infarction on daily aspirin therapy. Crit Care Med 38: 1423-1429.

Hobl EL, Jilma B, Ebner J, and Schmid RW (2013) Simultaneous determination of acetylsalicylic acid and salicylic acid in human plasma by isocratic high-pressure liquid chromatography with post-column hydrolysis and fluorescence detection. Biomed Chromatogr 27:695-698.

Hobl EL, Reiter B, Schoergenhofer C, Schwameis M, Derhaschnig U, Kubica J, Stimpfl T, and Jilma B (2016a) Morphine decreases ticagrelor concentrations but not its antiplatelet effects: a randomized trial in healthy volunteers. Eur J Clin Invest 46:7-14.

Hobl EL, Reiter B, Schoergenhofer C, Schwameis M, Derhaschnig U, Lang IM, Stimpfl T, and Jilma B (2016b) Morphine interaction with prasugrel: a doubleblind, cross-over trial in healthy volunteers. Clin Res Cardiol 105:349-355.

Hobl EL, Stimpfl T, Ebner J, Schoergenhofer C, Derhaschnig U, Sunder-Plassmann R, Jilma-Stohlawetz P, Mannhalter C, Posch M, and Jilma B (2014) Morphine decreases clopidogrel concentrations and effects: a randomized, double-blind, placebo-controlled trial. J Am Coll Cardiol 63:630-635.

Hogben CA, Schanker LS, Tocco DJ, and Brodie BB (1957) Absorption of drugs from the stomach. II. The human. J Pharmacol Exp Ther 120:540-545.

Jakl M, Sevcik R, Fatorova I, Horacek JM, and Pudil R (2017) High on-treatment platelet reactivity: risk factors and 5-year outcomes in patients with acute myocardial infarction. Anatol J Cardiol 17:113-118.

Jimenez AH, Stubbs ME, Tofler GH, Winther K, Williams GH, and Muller JE (1992) Rapidity and duration of platelet suppression by enteric-coated aspirin in healthy young men. Am J Cardiol 69:258-262.

Kubica J, Adamski P, Ostrowska M, Sikora J, Kubica JM, Sroka WD, Stankowska K, Buszko K, Navarese EP, Jilma B, et al. (2016a) Morphine delays and attenuates ticagrelor exposure and action in patients with myocardial infarction: the randomized, double-blind, placebo-controlled IMPRESSION trial. Eur Heart $J$ 37: $245-252$.

Kubica J, Kubica A, Jilma B, Adamski P, Hobl EL, Navarese EP, Siller-Matula JM, Dábrowska A, Fabiszak T, Koziński M, et al. (2016b) Impact of morphine on antiplatelet effects of oral P2Y12 receptor inhibitors. Int J Cardiol 215:201-208

Kurz A and Sessler DI (2003) Opioid-induced bowel dysfunction: pathophysiology and potential new therapies. Drugs 63:649-671.

Lichtenberger LM, Phan T, Fang D, Edler S, Philip J, Li-Geng T, and Dial EJ (2016) Bioavailability of aspirin in rats comparing the drug's uptake into gastrointestinal tissue and vascular and lymphatic systems: implications on aspirin's chemopreventive action. J Physiol Pharmacol 67:635-642.

McCarthy CP, Bhambhani V, Pomerantsev E, and Wasfy JH (2017) In-hospital outcomes in invasively managed acute myocardial infarction patients who receive morphine. J Interv Cardiol DOI: 10.1111/joic.12464 [published ahead of print]

McCarthy CP, Mullins KV, Sidhu SS, Schulman SP, and McEvoy JW (2016) The onand off-target effects of morphine in acute coronary syndrome: a narrative review. Am Heart J 176:114-121.

McEvoy JW, Ibrahim K, Kickler TS, Clarke WA, Hasan RK, Czarny MJ, Keramati AR, Goli RR, Gratton TP, Brinker JA, et al. (2018) Effect of intravenous fentanyl on ticagrelor absorption and platelet inhibition among patients undergoing percutaneous coronary intervention: the PACIFY randomized clinical trial (platelet aggregation with ticagrelor inhibition and fentanyl). Circulation 137:307-309.

Meine TJ, Roe MT, Chen AY, Patel MR, Washam JB, Ohman EM, Peacock WF, Pollack CV, Jr, Gibler WB, and Peterson ED CRUSADE Investigators (2005) Association of intravenous morphine use and outcomes in acute coronary syndromes: results from the CRUSADE quality improvement initiative. Am Heart $J$ 149: 1043-1049.

Mollace V, Rosano G, Malara N, Di Fabrizio E, Vitale C, Coluccio M, Maiuolo J, Ali Wasti A, Muscoli C, Gliozzi M, et al. (2017) Aspirin wears smart. Eur Heart $J$ Cardiovasc Pharmacother 3:185-188.

Montalescot G, van 't Hof AW, Lapostolle F, Silvain J, Lassen JF, Bolognese L, Cantor WJ, Cequier A, Chettibi M, Goodman SG, et al.; ATLANTIC Investigators (2014) Prehospital ticagrelor in ST-segment elevation myocardial infarction. N Engl J Med 371:1016-1027.

Nimmo WS, Heading RC, Wilson J, Tothill P, and Prescott LF (1975) Inhibition of gastric emptying and drug absorption by narcotic analgesics. $\mathrm{Br}$ J Clin Pharmacol 2:509-513

O'Gara PT, Kushner FG, Ascheim DD, Casey DE, Jr, Chung MK, de Lemos JA Ettinger SM, Fang JC, Fesmire FM, Franklin BA, et al. American College of Cardiology Foundation/American Heart Association Task Force on Practice Guidelines (2013) 2013 ACCF/AHA guideline for the management of ST-elevation myocardia infarction: a report of the American College of Cardiology Foundation/American Heart Association task force on practice guidelines [published correction appears in Circulation (2013) 128:e481]. Circulation 127:e362-e425. 
Parodi G (2016) Editor's choice-chest pain relief in patients with acute myocardial infarction. Eur Heart J Acute Cardiovasc Care 5:277-281.

Roth GJ and Majerus PW (1975) The mechanism of the effect of aspirin on human platelets. I. Acetylation of a particulate fraction protein. J Clin Invest 56:624-632. Schrör K (2016) Acetylsalicylic Acid, Wiley-VCH Verlag GmbH \& Co. KGaA, Weinheim, Germany.

Sibbing D, Kastrati A, and Berger PB (2016) Pre-treatment with P2Y12 inhibitors in ACS patients: who, when, why, and which agent? Eur Heart J 37:1284-1295.

Siller-Matula JM, Specht S, Kubica J, Alexopoulos D, De Caterina R, Hobl EL, Jilma B, Christ G, and Lang IM (2016) Abciximab as a bridging strategy to overcome morphine-prasugrel interaction in STEMI patients. $\mathrm{Br} J$ Clin Pharmacol 82 $1343-1350$.

Spiel AO, Bartko J, Schwameis M, Firbas C, Siller-Matula J, Schuetz M, Weigl M, and Jilma B (2011) Increased platelet aggregation and in vivo platelet activation after granulocyte colony-stimulating factor administration: a randomised controlled trial. Thromb Haemost 105:655-662.

Wiggins BS, Saseen JJ, Page RL II, Reed BN, Sneed K, Kostis JB, Lanfear D, Viran $\mathrm{S}$, and Morris PB; American Heart Association Clinical Pharmacology Committee of the Council on Clinical Cardiology; Council on Hypertension; Council on Quality of Care and Outcomes Research; and Council on Functional Genomics and Translational Biology (2016) Recommendations for management of clinically significant drug-drug interactions with statins and select agents used in patients with cardiovascular disease: a scientific statement from the American Heart Association. Circulation 134:e468-e495.

Yuan CS, Foss JF, O'Connor M, Roizen MF, and Moss J (1998) Effects of low-dose morphine on gastric emptying in healthy volunteers. J Clin Pharmacol 38: $1017-1020$

Yusuf S, Zhao F, Mehta SR, Chrolavicius S, Tognoni G, and Fox KK; Clopidogrel in Unstable Angina to Prevent Recurrent Events Trial Investigators (2001) Effects of clopidogrel in addition to aspirin in patients with acute coronary syndromes without ST-segment elevation. [published correction appears in $N$ Engl J Med (2001) 345:1716]. N Engl J Med 345:494-502.

Address correspondence to: Dr. Bernd Jilma, Department of Clinical Pharmacology, Medical University of Vienna, Waehringer Guertel 18-20, 1090 Vienna, Austria. E-mail: bernd.jilma@meduniwien.ac.at 